\title{
Treatment of lentigo maligna (Review)
}

\author{
JEAN KANITAKIS \\ Department of Dermatology (Pav. R), Ed. Herriot Hospital Group, 69437 Lyon Cedex 03, France
}

Received January 11, 2021; Accepted February 24, 2021

DOI: $10.3892 /$ wasj.2021.93

\begin{abstract}
Lentigo maligna (LM) is the most common type of in situ melanoma, usually appearing on chronically sun-exposed skin (mostly the head and neck) of elderly patients. It manifests clinically as a macule with a heterogeneous pigmentation and irregular contours. LM grows gradually over the years in a radial pattern and may eventually progress with a vertical growth phase, thereby transforming into an invasive melanoma (LM melanoma) that has potential for metastasis and a lethal outcome; accordingly, LM is currently regarded as an authentic melanoma in situ, rather than a premalignant condition. To the best of my knowledge, no prospective, randomized controlled studies evaluating the efficacy of the various treatment modalities applied for the treatment of LM exist to date. Surgical excision with tumour-free margins is regarded as the most effective treatment, achieving optimal rates of tumour clearance. Excision can be performed as traditional, one-step tumour ablation with predefined safety margins or, preferably, with margin-controlled techniques, such as staged excision or Mohs micrographic surgery, the latter methods achieving the highest cure rates. In the case of surgically-unresectable tumours or in frail patients with severe comorbidities, alternative non-surgical (off-label) therapies can be applied, including namely radiotherapy and imiquimod, as monotherapy or in various combinations.
\end{abstract}

\section{Contents}

1. Introduction

2. Principles of LM treatment

3. Surgical excision

4. Non-surgical treatments

5. Other treatments

6. Follow-up

Correspondence to: Professor Jean Kanitakis, Department of Dermatology (Pav. R), Ed. Herriot Hospital Group, 69437 Lyon Cedex 03, France

E-mail: jean.kanitakis@univ-lyon1.fr

Key words: lentigo maligna, lentigo maligna melanoma, Hutchinson's melanotic freckle, Melanosis circumscripta precancerosa of Dubreuilh, wide local excision, Mohs micrographic surgery, staged surgical excision, radiotherapy, imiquimod

\section{Introduction}

Lentigo maligna (LM), also known as malignant freckle, Hutchinson's melanotic freckle, Melanosis circumscripta precancerosa of Dubreuilh or melanoma in situ-LM type, is the most common clinicopathological subtype of in situ malignant melanoma (MM), accounting [along with lentigo maligna melanoma (LMM), its invasive counterpart] for $4-15 \%$ of all MM cases (1). Its incidence has been recently increasing worldwide, including in Europe (2,3), the USA (1) and Australia (4), as a consequence of ageing and the increased sun exposure of the population over the past decades. Australia seems to have the highest incidence of LM, estimated at 12.2 per 100,000 individuals (4).

Clinically, LM manifests as a flat macule with irregular contours and a variegate colour (Fig. 1). It is light- or dark-brown in colour, often with several hues, including black or whitish areas (reflecting partial regression), and may exceptionally be amelanotic. It develops on skin areas with high cumulative sun exposure, typically the head and neck (namely the cheeks, forehead, temple, periocular skin, nose and ears) and more rarely on extrafacial sun-exposed body zones (limbs) of middle-aged and elderly patients (mean age, 65 years) with fair skin, exhibiting signs of chronic sun damage, particularly in males (5); however, LM may be observed in younger patients in their 4th decade of life (6). In its early stage, LM may clinically mimic other pigmented facial lesions, such as solar lentigo, pigmented actinic keratosis, early seborrheic keratosis, lichenoid keratosis and pigmented basal cell carcinoma. LM grows radially over months or years [radial growth phase (RGP)] and may after months or years, invade the dermis (vertical growth phase), thereby progressing to invasive MM (LMM), which has potential for metastasis and a fatal outcome. The progression of LM to LMM manifests clinically with the appearance of a thickened zone or an infiltrated nodule, and pathologically belongs usually to the desmoplastic MM variant. The estimated lifetime risk of progression to LMM varies greatly (from 5-50\%). A recent Australian study estimated the annual risk of progression to LMM at $3.5 \%$, and the average time of progression to LMM at 28.3 years (7). As the delay to progression can be lengthy ( $>30$ years), this progression may not be observed within the lifespan of elderly individuals.

The diagnosis of LM is performed clinically and may be aided by non-invasive imaging techniques, such as dermatoscopy and in vivo reflectance confocal microscopy (RCM), which increase the sensitivity and specificity of diagnosis vs. simple visual inspection (8). By dermatoscopy, 
LM presents an atypical pseudonetwork characterized by different patterns, depending on the age of the lesion. These include, in chronological order, an annular-granular pattern due to the aggregation of blue-grey globules around follicular ostia; a greyish pseudonetwork secondary to thickening of the annular-granular structures; the asymmetric pigmentation of follicular openings (due to irregular atypical melanocyte infiltration of follicular ostia); greyish to black-brown rhomboidal pigmentation; homogeneous grey-blackish pigmented blotches due to obliteration of hair follicles; and reddish rhomboidal structures, scar-like whitish and milky-red areas; occasionally increased vascularity $(9,10)$. Grey colour was the most prevalent finding in one study (11). The use of deep learning convolutional neural network seems to have a high-level performance in the diagnosis of LMM (12). The major diagnostic criteria for LM by in vivo RCM include pagetoid infiltration of the epidermis by large $(>20 \mu \mathrm{m})$ dendritic or round hyperreflective cells and non-edged dermal papillae. Minor criteria include $\geq 3$ round or dendritic atypical cells at the dermal-epidermal junction in 5 fields of $0.5 \times 0.5 \mathrm{~mm}$, the localization of pagetoid and/or atypical junctional cells within hair follicles, and nucleated cells within the dermal papillae. On the basis of these findings, a 'LM score' has been proposed, which has a good diagnostic sensitivity (85-93\%) and specificity (61-76\%) (13). These non-invasive imaging methods, which can help differentiate LM from clinically similar-looking pigmented facial lesions, have gained popularity and are undoubtedly useful in the diagnosis of LM $(14,15)$; however, the histological examination of a skin biopsy still remains the gold standard for the definitive diagnosis of LM. For suspicious lesions, an excisional (elliptical) biopsy with narrow margins (1-3 $\mathrm{mm}$ ) around the lesion and under the anticipated deep limit of the lesion seems to be the most effective technique, as this minimizes the risk of missing the most invasive zone of the tumour; however, this is often not feasible for large facial lesions, which account for the majority of LM cases. An incisional or punch skin biopsy/ies is/are therefore often preferred, even though this procedure carries a higher risk for misdiagnosis (16). Indeed, an incisional (or punch) biopsy can easily rule out a non-melanocytic pigmented lesion which may clinically mimic LM (such as pigmented actinic keratosis or seborrheic keratosis); however, in the case of LM it may miss an invasive area which, if present, would be synonymous with invasive melanoma. Therefore, the biopsy/ies should be obtained from the clinically most suspicious area (most infiltrated, darkest or with the highest pigmentary irregularity). Dermatoscopy and in vivo RCM can assist in defining the most informative area from which biopsy/ies should be taken and can help to define the microscopic limits of the lesion, which is useful for the surgical treatment of LM, as atypical melanocytes often extend far beyond the clinically-visible limits of the lesion $(17,18)$. The biopsy of more than one site increases the sampling of the lesion and thereby reduces the risk of missing subclinical dermal invasion; indeed, up to $9-32 \%$ of cases diagnosed as LM by a partial (diagnostic) biopsy prove to be invasive (i.e., LMM) upon the examination of the completely-excised lesion (19-21).

The main histopathological feature of LM is a lentiginous proliferation of atypical melanocytes within the basal layer of the epidermis (Fig. 2). These cells may be naevoid, epithelioid or spindle-shaped, and often have a vacuolated cytoplasm and basophilic, occasionally multiple, nuclei. Atypical melanocytes are also frequently found within the basal epithelial layer of the hair-follicle epithelium and are responsible for recurrences following treatment modalities that do not penetrate deep enough in the dermis (22). Atypical melanocytes may form irregular junctional nests and may later invade the dermis, initiating a vertical growth phase (LMM). Two major patterns of RGP have been described, i.e. a 'classic' pattern with a dense proliferation of atypical melanocytes along the dermal-epidermal junction with few nests, and a naevoid (or dysplastic nevus-like LM) characterized by more prominent nest formation with occasional bridging of adjacent rete ridges. Additional histologic findings include atrophy of the epidermis (that has a flattened dermal-epidermal junction), severe actinic dermal elastosis (reflecting chronic sun-damage) and infiltration of the upper dermis with melanophages and some lymphocytes (23). LM should be distinguished from atypical melanocytic hyperplasia (solar melanocytosis), which is often found in chronically sun-exposed skin of the face; this differentiation may be difficult, particularly in early LM. Immunostaining for the cancer testis antigen, PRAME, seems to be a promising tool to this effect (24).

According to the latest edition of the WHO classification of skin tumours (2018), LM is classified among melanomas with high cumulative sun damage, due to the activation of the signaling pathway II. LM carries predominantly mutations in the NRAS, KIT and BRAF (non-V600E) genes, more rarely of the NF1, TERT, CDKN2a, TP53, PTEN and RACI genes $(23,25)$.

\section{Principles of LM treatment}

To date, to the best of my knowledge, there are no available prospective or randomised controlled trials allowing the establishment of definite guidelines for the management of LM (26). It is however, generally admitted that, as for other melanoma forms, the most effective treatment for LM is complete surgical excision, since this achieves the highest cure rates. However, clinical factors, such as the patient's age, life expectancy and comorbidities, and the size and location of the lesion affect the manner in which LM is treated. Other destructive or medical treatments can be proposed when surgery is not a feasible option due to patient- or lesion-related factors. The most appropriate treatment should be tailored to each individual patient, if necessary in the setting of a multidisciplinary oncology team, the aim being to offer the optimal risk-benefit ratio to each patient.

\section{Surgical excision}

Complete surgical excision with clear histological margins is the best treatment of LM. Indeed, this allows the histopathological assessment of excision margins to ensure complete tumour removal, allows the detection of a clinically inapparent invasive component (in which case the management will be more aggressive) and removes hair follicles where atypical melanocytes may exist, thereby decreasing the risk of recurrence. Surgical excision achieves higher clearance rates than those achieved by non-surgical treatments (27) and is therefore 


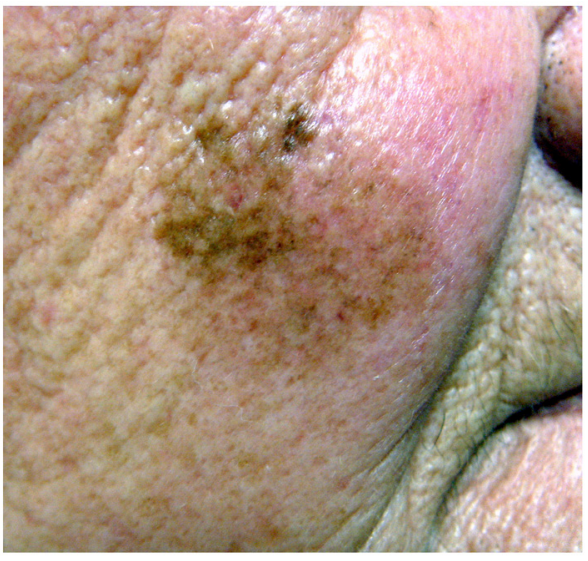

Figure 1. Lentigo maligna on the cheek of an elderly patient manifesting as a large, ill-defined macule with heterogeneous pigmentation.

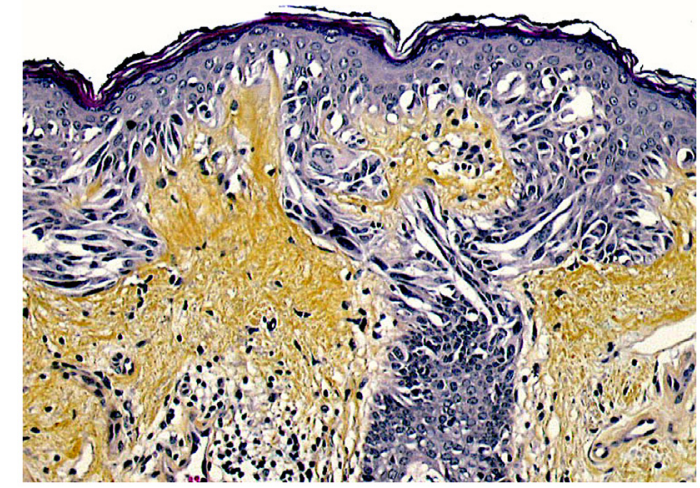

Figure 2. Microscopic aspect of lentigo maligna: A lentiginous proliferation of atypical melanocytes within the basal epidermal cell layer is seen (haematoxylin-eosin-saffron stain, original magnification, x250).

considered the first-line treatment of LM. The definite surgical excision should preferably be performed within 4-6 weeks following the diagnosis of LM. The aim is to excise the lesion completely (i.e., with tumour-free margins), while conserving a maximum of healthy tissue, so as to entail the least possible aesthetic and functional prejudice and maximize the patient's quality of life.

Surgical excision is performed with various modalities, such as standard (wide) excision with predefined safety margins, or with techniques with complete peripheral margin assessment [staged surgical excision (SSE)]. These include mainly radial sections, the square method, the perimeter technique, the 'spaghetti' technique and Mohs micrographic surgery (MMS). Compared to wide excision (WE), microscopically-controlled SSE achieves better results in terms of recurrence (28), although a recent study did not find better survival rates of patients treated for LM of the trunk and limbs with MMS vs. wide local excision (29).

$W E$. WE is performed as a one-stage procedure using predefined safety margins. It is suitable for well-defined, relatively small LM and extrafacial LM. A histological examination is performed on routinely-processed (formalin-fixed, paraffin-embedded) tissue sections, usually prepared with the 'bread-loaf' technique. However, the size of safety margins is a matter of debate. For in situ MM of the trunk and extremities, the majority of consensus guidelines recommend excision margins of $5 \mathrm{~mm}$ around the visible lesion; however, in LM there is often a subclinical extension of atypical melanocytes, which may be present several centimetres beyond the visible lesion, so that in approximately half of all LM cases, $5 \mathrm{~mm}$ margins are not sufficient to achieve histologically-negative margins (30). One study found that the mean surgical margin required for complete LM excision was $7.1 \mathrm{~mm}$ (31). Another study demonstrated that a clearance rate of $94 \%$ could be achieved with a wider (up to $1.5 \mathrm{~cm}$ ) margin (19). A more recent study suggested that initial surgical margins of at least $12 \mathrm{~mm}$ should be used to achieve histologically negative margins in $97 \%$ of head/neck primary melanomas (32). In a prospective study on 1,120 patients with MM in situ treated by MMS, surgical margins of 6 and $9 \mathrm{~mm}$ resulted in the removal of 86 and $99 \%$ of the tumours, respectively (33). On the basis of such studies, the French guidelines recommend margins of $1 \mathrm{~cm}$; when this margin is unfeasible due to anatomic or functional limitations, a margin of $5 \mathrm{~mm}$ is acceptable, pending strict microscopic control of the entire tumour margin, either with SSE or MMS prior to definitive would closure (34). The European consensus guidelines recommend margins of 5 up to $10 \mathrm{~mm}$, and for larger lesions, microscopically-controlled surgery (35). The National Comprehensive Cancer Network (36) and the American Academy of Dermatology (37) also recommend margins 5-10 $\mathrm{mm}$ for in situ MM; however, it should be acknowledged that complete excision may require wider margins and/or margin control techniques that allow histologic assessment of the entire peripheral margin. The optimal deep margin of excision has not been adequately investigated to date; this commonly includes the deep subcutaneous fat (37), but not the aponeurosis, since removing this structure does not improve the rate of recurrence (or survival, in the case of LMM).

Standard WE with predefined margins achieves clearance rates ranging from 24 to $70 \%$, which are lower than those achieved with techniques with complete peripheral margin assessment (27). Another limitation of standard WE followed by immediate reconstruction is the difficulty to localize the residual tumour if the margins are not tumour-free, particularly following complex tissue reconstruction. This can be avoided with surgical techniques allowing for complete margin assessment. Margin-controlled excisions are indicated for most LM of the face and for large LM with ill-defined clinical borders.

SSE. SSE techniques comprise several consecutive stages of excision, with each stage defined by the histologic findings of the previous stage. The first stage(s) is excision of peripheral margins, if necessary in multiple steps, until histologically tumour-free ones are obtained; this is followed by the excision of the main tumour. SSE is based on the examination of paraffin-embedded tissue specimens, which ensures a more reliable histopathologic interpretation of the margins, if necessary with the addition of immunohistochemical staining for melanocytic antigens (such as Melan-A, HMB-45, SOX-10 and PRAME) (38). These techniques do not leave the patients with an open wound prior to final reconstruction; however, they entail a delay of at least $24 \mathrm{~h}$ before the re-excision and closure of the defect/reconstruction can be performed, usually 
with flaps or grafts. The recurrence rate achieved with SSE is reportedly $<10 \%$; one comparative study found it significantly lower than that obtained with MMS (39). Various SSE techniques have been developed: i) SSE with radial vertical sections includes the traditional excision of the main tumour (debulk) followed by the excision of 4 peripheral quadrants (with 5-7 mm margins) which are marked so as to allow their precise mapping (31). The wound is left open until the pathological examination reports clear margins. Each quadrant is routinely-processed and cut radially at 1-2 mm intervals in a clockwise manner, which allows visualization of their external/distant margins. These are considered clear if no atypical melanocytes are found $>2 \mathrm{~mm}$ from the peripheral margin, otherwise additional $2-3 \mathrm{~mm}$ quadrants are excised and processed in the same manner, until clear margins are obtained. Permanent closure of the wound can subsequently by performed. This technique achieves a low recurrence rate ( $<5 \%$ at 5.9 years) (40). ii) The 'square technique' consists of defining a square margin around the lesion and excising thin (2-4 $\mathrm{mm}$ ) strips around it with a double-bladed scalpel, while the tumour is left in place and the resulting defect sutured (41). The strips are routinely-processed and sectioned vertically, which allows to examine the whole periphery of the square. If the margins are not tumour-free, additional (peripheral) skin strips are excised and examined until clear margins are obtained; this is followed by total excision of the tumour. With this technique clearance rate of $97.7 \%$ has been reported, with a long follow-up (42). iii) The 'spaghetti' technique is similar, but involves the excision of a non-angled strip peripheral to the tumour, parallel to its contour, with a double-edged scalpel; this is simpler than MMS, and can be used to map the lesion before it is finally removed (39).

MMS.MMS is a specialized form of SSE allowing for total margin assessment. This is achieved similar to the SSE techniques, by first debulking the main tumour with margins of 3-6 mm, and then obtaining tissue strips peripheral and deep to the main tumour with immediate examination of frozen sections stained with haematoxylin-eosin. The margins are examined intraoperatively until clear ones are obtained, allowing for the immediate closure of the wound. A limitation of MMS lies in the difficulty in assessing histologically atypical melanocytes (particularly when they are scattered within the basal epidermal layer) due to the poor quality of frozen tissue sections; immunohistochemical stains for melanocytic antigens (such as gp100/HMB-45 or PRAME) can be used to improve the visualization of atypical melanocytes. This problem probably accounts (at least in part) for the rare recurrences following 'complete' excision of LM by MMS. An alternative technique (known as 'slow Mohs') is the examination of routinely-processed (formalin-fixed, paraffin-embedded) sections, which provide a better visualization of tumour cells (43). As with the above-mentioned SSE techniques, the 'slow Mohs' entails a delay of at least 1 day prior to the definitive closure of the wound. MMS allows smaller initial margins than those of standard excision, and therefore has the advantage of sparing healthy tissue (although in LM the difference with SSE regarding post-surgical lesion size may not be significant). The recurrence rate of LM following MMS is usually in the order of 4-5\% (44-47), and in some studies, even lower $(0.1-0.5 \%)(48,49)$.

\section{Non-surgical treatments}

Non-surgical treatments may be envisaged in some clinical settings, namely when complete excision would entail unacceptable mutilations, or in elderly or frail patients in whom comorbidities or advanced age render surgery impossible. These non-surgical modalities entail lower morbidity and cosmetic impact; conversely, however, they carry a higher risk of recurrence compared with surgical excision, namely due to the lack of histological tumour assessment, a fact also exposing to the risk of missing invasive MM (LMM). Non-surgical treatment options include the following.

Radiotherapy $(R T)$. RT has been used for decades for the treatment of MM, including LM, although nowadays it is not considered as the primary treatment option. It is however, included in current European treatment guidelines $(35,50)$ as a second-line treatment for selected patients in whom surgical therapies are not possible or undesirable by the patient. A prospective multisite international randomized controlled phase 3 trial of RT vs. imiquimod (IMQ) for histologically-confirmed LM is underway (RADICAL, NCT02394132) and is expected to provide data with a high level of evidence which may influence future guidelines for the management of LM.

A recent literature review identified 14 series of patients with LM mainly (79-100\%) of the head/neck area (total of 1,075 lesions) treated with RT in Europe and the USA from 1940 to 2014 (51). A wide range of modalities of RT have been applied, and include mainly low-energy (soft) Grenz rays (GR) and superficial X-rays ('contact RT'). GR (more commonly used by dermatologists) have an energy range $10-30 \mathrm{kV}$ and limited tissue penetration (half-dose depth of about $1 \mathrm{~mm}$ ), whereas superficial X-rays (preferred by radiation oncologists) have an energy of 30-150 $\mathrm{kV}$ and a deeper tissue penetration (half-dose depth of approximately $\geq 1 \mathrm{~cm}$ ).

GR RT has been administered at total doses of 40-160 Gy in 3-13 fractions, every 1 to 4 days (single fraction dose of 10-20 Gy). Superficial RT is more commonly delivered at lower total doses (35-60 Gy), in 5-23 fractions every 1 to 4 days (single fraction dose 2.5-7 Gy) (51). A minimum of 3 fractions per week has been recommended (52). The radiation field must be sufficiently large to account for microscopic tumour extension, so as to avoid recurrences; it ranges between 5 and $10 \mathrm{~mm}$ around the visible lesion, up to $20 \mathrm{~mm}$ in some studies (53). The radiation should reach deeply-seated melanocytes (namely those contained in hair follicles), considering that the radiation energy decreases with increasing depth; $5 \mathrm{~mm}$ is considered sufficient in most cases. In this respect, superficial RT (or high energy GR) is favoured by several authors, as this allows the wider coverage of the target volume, including the skin appendages $(51,52)$. GR RT can nevertheless achieve a high rate of control rates $(90 \%)(54,55)$, although an older study from the USA reported much lower control rates (56). The recurrence rates varied from 0 to $31 \%$, both for GR and superficial RT, with a follow-up time of 15 to 96 months (53-55,57-62). Pigmentation disappeared within 1-24 months following RT. An assessment of the result 6 months following RT completion is advised. Recurrences have been reported up to 9 years post-treatment, therefore continuous follow-up seems necessary. 
Additional RT techniques include brachytherapy and external beam RT. Brachytherapy involves the application to the skin of a mould containing radioactive sources (tubes or wires); it can irradiate large areas but necessitates an expert construction and skill. External beam RT is made of either photons (superficial RT) or electrons (52).

The cosmetic results of RT were reportedly in most cases good to excellent, although late complications may develop, such as telangiectasias, atrophy and hyper- or hypo-pigmentation $(57,61)$; however, no fibrosis or ulceration were reported, and the risk of new skin cancer development due to RT in this population of elderly patients does not seem concerning. RT may also be administered as adjuvant treatment following incomplete surgical excision, or when LM is detected post-surgery by dermatoscopy or in vivo RCM. In these cases, $\mathrm{RT}$ doses may need to be increased (52).

Topical IMQ. This is a recommended treatment when both surgery and RT are not appropriate or not preferred by the patient (63). IMQ [1-(2-2methylpropyl)-1H-imidazo(4,5-c) quinolin-4-amine] is a synthetic Toll-like receptor 7-agonist approved for the topical treatment of genital warts, actinic keratoses and superficial basal-cell carcinomas. It is an immune-response modifier, stimulating skin macrophages to secrete several cytokines [such as interleukin (IL)-6, IL-1 $\alpha$, IL-8, IL-12, tumour necrosis factor (TNF) $\alpha$, interferon (IFN)- $\alpha$, IFN- $\gamma$, granulocyte-macrophage colony-stimulating factor (GM-CSF) and granulocyte colony-stimulating factor (G-CSF)] which exert antiviral and antitumour effects. Local inflammatory side-effects (redness, burning sensation and erosions) frequently develop, and may cause burden to the patient; however, inflammation seems to be associated with the efficacy of treatment (64).

IMQ (available in European countries as 5\% cream) can be used as an off-label treatment in different settings; i.e., as a neoadjuvant therapy prior to surgery in order to reduce tumour size (65), as primary monotherapy in selected patients who are not candidates to (or refuse) surgical excision, or as adjuvant therapy following excision. The dosing schemes are variable, varying from twice daily to 5 times weekly applications over a period of several weeks (6-44), with treatment margins from 0.5 to $2 \mathrm{~cm}$ around the visible lesion. In some studies, an escalation of the dosing scheme was performed so as to reach an inflammatory response, up to twice daily 7 days/week for 10 weeks $(64,66)$. In the majority of studies $(67-71)$ the follow-up time was relatively short, usually $<3$ years. The clearance rates reportedly range between 72 and $93 \%$; however, approximately $27 \%$ of patients exhibit residual LM on histological analysis (66). An 'intensive' treatment (daily applications $>12$ weeks) resulted in a high (74\%) clinical and microscopic clearance rate (72). A recent study also reported a $72 \%$ long-term (4.1-year) clearance rate following IMQ treatment once or twice daily for up to 22 weeks (64). Clinical recurrences following primary IMQ therapy develop in 4-24\% of cases after an average of 3.2 years (72-74) and seem to be more common for LM of the nose (75). The development of an inflammatory reaction to IMQ seems to be associated with a better clinical and histological response (64,76-78), contrary to lesion size and treatment duration. Factors found to be predictive of local recurrence include the total number of melanocytes, the number of basal and suprabasal melanocytes and the number of pagetoid spreading melanocytes (73). Responses are associated with an increased programmed death-ligand 1 (PD-L1) expression and the upregulated expression of genes involved in antigen presentation, T-cell activation and type I IFN signalling, which could be used as biomarkers of LM response to IMQ (79). IMQ can be used in association with local applications of tazarotene $0.1 \%$ gel twice-weekly; this decreases stratum corneum cohesion, and thereby increases IMQ penetration $(70,80,81)$, and has achieved a slightly better, although statistically not-significant, clearance rate (80). A review of published studies as of 2015 concluded that IMQ as monotherapy for LM achieves clinical and histologic clearance rates of 78.3 and $76.2 \%$, respectively. Clinical recurrences occur in $2.3 \%$ of cases, following a mean follow-up of 34 months. A higher likelihood of histologic clearance is obtained with $>60$ total applications or with $>5$ weekly applications (82); however, lower pathological and clinical clearance rates (37 and 43\%, respectively) were reported in a more recent study (83); furthermore, progression to LMM has also been observed after IMQ treatment (84-86). Surgical excision can be performed in case of persisting LM, and this further reduces the 5-year recurrence rate (66). Patients treated with IMQ should be followed in the long-term (at least for 5 years) and post-treatment biopsies are recommended even if no recurrence is observed clinically (87). RCM is useful to monitor the response to medical treatments, including IMQ (88).

IMQ can also be used before SE in order to reduce the size of the required surgical margins, or as an adjuvant treatment in patients with positive margins after adequate surgery, or after laser ablation. In a recent study, IMQ 5\% was applied as neoadjuvant treatment for an average of 2.5 months before staged excisions. This necessitated a mean surgical margin of $3.5 \mathrm{~mm}$ and resulted in a recurrence rate of $3.9 \%$, i.e., similar to reported recurrence rates with SSE by either MMS or en face permanent sections; the mean time to recurrence was 4.3 years and the mean follow-up time 5.5 years (81).

\section{Other treatments}

Other treatment modalities have been used for LM, but are not included in current consensus guidelines due to unproven or low efficacy. These include the following.

Cryotherapy. This technique consists of an application of a cryogenic agent (usually liquid nitrogen) to the skin in order to destroy superficially-located tumour cells. Melanocytes are more sensitive than keratinocytes to freezing, being destroyed at temperatures between -4 and $-7^{\circ} \mathrm{C}$. The majority of relevant studies have included small series of patients with LM. A total of 2-3 freeze-thaw cycles (possibly under local anaesthesia) are usually applied with 5-10 mm lesion margins. Although good results have been reported by some authors (89), other researchers have found high (up to $40 \%$ ) recurrence rates (90). Cryotherapy may make subsequent progression difficult to detect, and has been complicated by the development of amelanotic MM (91). Hyper- or hypo-pigmentation of the treated area is a possible side-effect (90). Some researchers have used a combination of cryotherapy with IMQ (cryo-immunological treatment or 'immunocryosurgery') (3). 
Photodynamic therapy (PDT). PDT consists of an application of a photosensitizer (usually aminolevulinate) followed by illumination with red light at $635 \mathrm{~nm}$. It has been used in small patient series and has resulted in an $80 \%$ clearance rate (92). More recently, PDT assisted by ablative fractional laser was used in order to increase the absorption of the photosensitizer, and achieved a 70\% histological clearance rate (93).

Laser therapy. Various types of lasers (including Q-switched ruby, Q-switched neodymium-doped yttrium aluminium garnet, carbon dioxide, argon, alexandrite and various combinations) have been used for the ablation of LM (94-96). Potential advantages include better cosmetic results compared with surgery, less pain, speed of therapy and less post-treatment care. The clearance rates are variable, $100 \%$ in one study (97), but lower in others (60-80\%), probably as the laser beam may not reach a sufficient depth to destroy atypical melanocytes seated deeply within hair follicles, which is a drawback of laser therapy. The combination of ablative laser therapy followed by IMQ has recently been advocated, but recurrences seemed to be frequent, particularly on the nose (75).

Curettage and electrodessication. A small number of patients have been treated with this modality, with rather high recurrence rates (98).

Topical azelaic acid (AZA). AZA is a dicarboxylic acid that competitively inhibits tyrosinase in vitro. On this basis, it has been tried for the treatment of LM (applications of 15-20\% cream for up to 3 months). Local disease control has been reported; however, progression to invasive melanoma has also occurred (99).

Topical 5-fluorouracil (5-FU). This is an antitumour analogue of pyrimidine approved as 5\% cream for the topical treatment of actinic keratoses and superficial basal cell carcinomas. It has been tried in the treatment of LM (twice daily applications for 6-13 weeks); however, recurrences were very common $(100,101)$.

Topical cidofovir $1 \%$. This is an acyclic nucleoside analogue of deoxycytidine monophosphate that may block DNA synthesis; it has been used topically for the treatment of DNA viral infections (HPV warts, molluscum contagiosum, herpes simplex) and has proven effective in a small number of basaland squamous-cell carcinomas and in two cases of recurring LM (102).

Ingenol mebutate (IM). IM is a diterpene ester obtained from the plant Euphorbia peplus, and was licensed some years ago for the treatment of actinic keratoses. It has been tried in a small number of patients with LM, although the results have been rather disheartening $(103,104)$. IM was recently withdrawn from the European market, although it is still commercially available in other parts of the world.

Finally, elderly patients with facial LM that are not suspicious of being invasive and who are unable (or refuse) to receive aggressive treatments may be closely monitored with non-invasive imaging techniques (macroscopic and dermatoscopic photography, in vivo RCM) and undergo skin biopsy if changes suggestive of progression to LMM occur. This conservative watchful attitude was preferred by almost $20 \%$ of European dermatologists for patients $>70$ years of age (105).

LMM has the same prognosis as other MM subtypes when adjusted for Breslow thickness and other prognostic factors, and should therefore be treated according to the guidelines established for other MM types, even though the localization on the face and the size of the lesion often pose challenging functional and anatomic problems. The therapeutic decision should be tailored to each patient on an individual basis after discussion in the setting of a multidisciplinary oncology team.

\section{Follow-up}

Patients with MM should undergo a regular clinical follow-up in order to detect as early as possible recurrences and the development of new primary MM (which occur in $10 \%$ of patients). Follow-up should also provide psychosocial support and education on self-examination of the patient and his close family members. The extent and frequency of follow-up examinations depend on the risk of each patient. Since LM has no risk of metastasis, some authors advocate no follow-up, apart from a visit after complete excision to check for new primary $\mathrm{MM}$, and to teach self-examination for a new MM. Apart from patient self-examination, however, the majority of guidelines recommend dermatological examination every 6 months for 3 years, and thereafter once yearly for life (or at least during 10 years for the detection of new MM or other skin cancers).

\section{Acknowledgements}

Not applicable.

\section{Funding}

No funding was received.

\section{Availability of data and materials}

Not applicable.

\section{Author's contribution}

JK conceived and designed the study, performed the literature search, and wrote and revised the manuscript. The author has read and approved the final manuscript.

\section{Ethics approval and consent to participate}

The clinical image depicted in Fig. 1 and the pathological image depicted in Fig. 2 were obtained several years ago at the Department of Dermatology, Ed. Herriot Hospital, Lyon, France, and are part of a medical anonymous sample collection. They are only depicted herein retrospectively as examples of the disease and its pathology.

\section{Patient consent for publication}

Not applicable. 


\section{Competing interests}

The author declares that he has no competing interests.

\section{References}

1. Swetter SM, Boldrick JC, Jung SY, Egbert BM and Harvell JD: Increasing incidence of lentigo maligna melanoma subtypes: Northern California and national trends 1990-2000. J Invest Dermatol 125: 685-691, 2005.

2. Greveling K, Wakkee M, Nijsten T, van den Bos RR and Hollestein LM: Epidemiology of lentigo maligna and lentigo maligna melanoma in the Netherlands, 1989-2013. J Invest Dermatol 136: 1955-1960, 2016.

3. Matas-Nadal C, Sòria X, García-de-la-Fuente MR, Huerva V, Ortega E, Vilardell F, Gatius S, Casanova JM and Martí RM: Immunocryosurgery as monotherapy for lentigo maligna or combined with surgical excision for lentigo maligna melanoma. J Dermatol 45: 564-570, 2018.

4. Guitera P, Collgros H, Madronio C, Goumas C, Mann GJ, Watts CG, Pereira AR, Armstrong BK, Drummond M, Morton RL, et al: The steadily growing problem of lentigo maligna and lentigo maligna melanoma in Australia: Population-based data on diagnosis and management. Australas J Dermatol 60 $118-125,2019$

5. Higgins H II, Cho E, Weinstock MA, Li TY, Qureshi A and Li WQ: Gender differences, UV exposure and risk of lentigo maligna in a nationwide healthcare population cohort study. J Eur Acad Dermatol Venereol 33: 1268-1271, 2019.

6. Duarte AF, Sousa-Pinto B, Barros AM, Haneke E and Correia O: Lentigo maligna-not always a face and neck disease of the elderly. Dermatology 234: 37-42, 2018.

7. Menzies SW, Liyanarachchi S, Coates E, Smith A, CookeYarborough C, Lo S, Armstrong B, Scolyer RA and Guitera P. Estimated risk of progression of lentigo maligna to lentigo maligna melanoma. Melanoma Res 30: 193-197, 2020

8. Cinotti E, Labeille B, Debarbieux S, Carrera C, Lacarrubba F, Witkowski AM, Moscarella E, Arzberger E, Kittler H, Bahadoran P, et al: Dermoscopy vs reflectance confocal microscopy for the diagnosis of lentigo maligna. J Eur Acad Dermatol Venereol 32: 1284-1291, 2018

9. Pralong P, Bathelier E, Dalle S, Poulalhon N, Debarbieux S and Thomas L: Dermoscopy of lentigo maligna melanoma: Report of 125 cases. Br J Dermatol 167: 280-287, 2012.

10. Agozzino M, Vitiello $P$ and Nuzzo T: Lentigo maligna. In: Argenziano G, Moscarella E, Piccolo V, Agozzino M, Longo C and Pellacani G (eds). Color Atlas of Dermoscopy PICCIN press, Padova, pp127-129, 2020.

11. Tiodorovic-Zivkovic D, Argenziano G, Lallas A, Thomas L, Ignjatovic A, Rabinovitz H, Moscarella E, Longo C, Hofmann-Wellenhof R and Zalaudek I: Age, gender, and topography influence the clinical and dermoscopic appearance of lentigo maligna. J Am Acad Dermatol 72: 801-808, 2015.

12. Winkler JK, Sies K, Fink C, Toberer F, Enk A, Deinlein T, Hofmann-Wellenhof R, Thomas L, Lallas A, Blum A, et al Melanoma recognition by a deep learning convolutional neural network-performance in different melanoma subtypes and localisations. Eur J Cancer 127: 21-29, 2020.

13. Guitera P, Moloney FJ, Menzies SW, Stretch JR, Quinn MJ, Hong A, Fogarty G and Scolyer RA: Improving management and patient care in lentigo maligna by mapping with in vivo confocal microscopy. JAMA Dermatol 149: 692-698, 2013.

14. Lallas A, Argenziano G, Moscarella E, Longo C, Simonetti V and Zalaudek I: Diagnosis and management of facial pigmented macules. Clin Dermatol 32: 94-100, 2014.

15. Star P and Guitera P: Lentigo maligna, macules of the face, and lesions on sun-damaged skin: Confocal makes the difference. Dermatol Clin 34: 421-429, 2016.

16. Ng JC, Swain S, Dowling JP, Wolfe R, Simpson P and Kelly JW: The impact of partial biopsy on histopathologic diagnosis of cutaneous melanoma: Experience of an Australian tertiary referral service. Arch Dermatol 146: 234-239, 2010.

17. Champin J, Perrot JL, Cinotti E, Labeille B, Douchet C, Parrau G, Cambazard F, Seguin P and Alix T: In vivo reflectance confocal microscopy to optimize the spaghetti technique for defining surgical margins of lentigo maligna. Dermatol Surg 40: 247-256, 2014.
18. Yelamos O, Cordova M, Blank N, Kose K, Dusza SW, Lee E, Rajadhyaksha M, Nehal KS and Rossi AM: Correlation of handheld reflectance confocal microscopy with radial video mosaicing for margin mapping of lentigo maligna and lentigo maligna melanoma. JAMA Dermatol 153: 1278-1284, 2017.

19. Agarwal-Antal N, Bowen GM and Gerwels JW: Histologic evaluation of lentigo maligna with permanent sections: Implications regarding current guidelines. J Am Acad Dermatol 47: 743-748, 2002.

20. Möller M, Pappas-Politis E, Zager JS, Santiago LA, Yu D, Prakash A, Kinal A, Clark GS, Zhu W, Puleo CA, et al: Surgical management of melanoma-in-situ using a staged marginal and central excision technique. Ann Surg Oncol 16: 1526-1536, 2009.

21. Zoutendijk J, Tio D, Koljenovic S and van den Bos RR: Nine per cent of biopsy-proven lentigo maligna lesions are reclassified as lentigo maligna melanoma after surgery. Br J Dermatol 181: 383-384, 2019.

22. Connolly KL, Giordano C, Dusza S, Busam KJ and Nehal K: Follicular involvement is frequent in lentigo maligna: Implications for treatment. J Am Acad Dermatol 80: 532-537, 2019.

23. Elder DE, Bastian BC, Kim J, Massi D, Mihm M, Scolyer R and Wood B: Lentigo maligna melanoma. In: WHO Classification of Skin Tumours. 4th edition. Elder DE, Massi D, Scolyer RA and Willemze R (eds). International Agency for Research on Cancer, Lyon, pp102-104, 2018.

24. Tio D, Willemsen M, Krebbers G, Kasiem FR, Hoekzema R, van Doorn R, Bekkenk MW and Luiten RM: Differential expression of cancer testis antigens on lentigo maligna and lentigo maligna melanoma. Am J Dermatopathol 42: 625-627, 2020

25. Elder DE, Bastian BC, Cree IA, Massi D and Scolyer RA: The 2018 world health organization classification of cutaneous, mucosal and uveal melanoma. Detailed analysis of 9 distinct subtypes defined by their evolutionary pathway. Arch Pathol Lab Med 144: 500-522, 2020.

26. Tzellos T, Kyrgidis A, Mocellin S, Chan AW, Pilati P and Apalla Z: Interventions for melanoma in situ, including lentigo maligna. Cochrane Database Syst Rev: Dec 19, 2014. doi: 10.1002/14651858.CD010308.pub2.

27. McLeod M, Choudhary S, Giannakakis G and Nouri K: Surgical treatments for lentigo maligna: A review. Dermatol Surg 37: 1210-1228, 2011.

28. de Vries K, Greveling K, Prens LM, Munte K, Koljenović S, van Doorn MB and Prens EP: Recurrence rate of lentigo maligna after micrographically controlled staged surgical excision. Br J Dermatol 174: 588-593, 2016

29. Demer AM, Hanson JL, Maher IA and Liszewski W: Association of Mohs micrographic surgery vs wide local excision with overall survival outcomes for patients with melanoma of the trunk and extremities. JAMA Dermatol 157: 84-89, 2021.

30. McGuire LK, Disa JJ, Lee EH, Busam KJ and Nehal KS: Melanoma of the lentigo maligna subtype: Diagnostic challenges and current treatment paradigms. Plast Reconstr Surg 129: 288e-299e, 2021.

31. Hazan C, Dusza SW, Delgado R, Busam KJ, Halpern AC and Nehal KS: Staged excision for lentigo maligna and lentigo maligna melanoma: A retrospective analysis of 117 cases. J Am Acad Dermatol 58: 142-148, 2008.

32. Ellison PM, Zitelli JA and Brodland DG: Mohs micrographic surgery for melanoma: A prospective multicenter study. J Am Acad Dermatol 81: 767-774, 2019.

33. Kunishige JH, Brodland DG and Zitelli JA: Surgical margins for melanoma in situ. J Am Acad Dermatol 66: 438-444, 2012.

34. Guillot B, Dalac S, Denis MG, Dupuy A, Emile JF, De La Fouchardiere A, Hindie E, Jouary T, Lassau N, Mirabel X, et al: French updated recommendations in stage I to III melanoma treatment and management. J Eur Acad Dermatol Venereol 31: 594-602, 2017.

35. Garbe C, Amaral T, Peris K, Hauschild A, Arenberger P, Bastholt L, Bataille V, Del Marmol V, Dréno B, Fargnoli MC, et al: European consensus-based interdisciplinary guideline for melanoma. Part 2: Treatment-update 2019. Eur J Cancer 126: 159-177, 2020.

36. National Comprehensive Cancer Network. https://www.ncen. org/professionals/physician_gls/pdf/cutaneous_melanoma.pdf. Accessed December 19,2020

37. Swetter SM, Tsao H, Bichakjian CK, Curiel-Lewandrowski C, Elder DE, Gershenwald JE, Guild V, Grant-Kels JM, Halpern AC, Johnson TM, et al: Guidelines of care for the management of primary cutaneous melanoma. J Am Acad Dermatol 80: 208-250, 2019. 
38. Gradecki SE, Valdes-Rodriguez R, Wick MR and Gru AA PRAME immunohistochemistry as an adjunct for diagnosis and histological margin assessment in lentigo maligna. Histopathology: Dec 6, 2020 (Epub ahead of print).

39. Gaudy-Marqueste C, Perchenet AS, Taséi AM, Madjlessi N, Magalon G, Richard MA and Grob JJ: The 'spaghetti technique': An alternative to Mohs surgery or staged surgery for problematic lentiginous melanoma (lentigo maligna and acral lentiginous melanoma). J Am Acad Dermatol 64: 113-118, 2011.

40. Connolly KL, Hibler BP, Lee EH, Rossi AM, Busam KJ and Nehal KS: Locally recurrent lentigo maligna and lentigo maligna melanoma: Characteristics and time to recurrence after surgery. Dermatol Surg 43: 792-797, 2017.

41. Johnson TM, Headington JT, Baker SR and Lowe L: Usefulness of the staged excision for lentigo maligna and lentigo maligna melanoma: The 'square' procedure. J Am Acad Dermatol 37: 758-764, 1997.

42. Smith H, Olabi B, Lam M, Patel A and Varma S: Ten years' experience using the Johnson square procedure for lentigo maligna Br J Dermatol 181: 602-604, 2019

43. Hilari H, Llorca D, Traves V, Villanueva A, Serra-Guillén C, Requena C, Llombart B, Sanmartín O, Guillén C and Nagore E: Conventional surgery compared with slow Mohs micrographic surgery in the treatment of lentigo maligna: A retrospective study of 62 cases. Actas Dermosifiliogr 103: 614-623, 2012 (In English, Spanish).

44. Bene NI, Healy C and Coldiron BM: Mohs micrographic surgery is accurate $95.1 \%$ of the time for melanoma in situ: A prospective study of 167 cases. Dermatol Surg 34: 660-664, 2008.

45. Erickson C and Miller SJ: Treatment options in melanoma in situ: Topical and radiation therapy, excision and Mohs surgery. Int J Dermatol 49: 482-491, 2010.

46. Sharma AN, Foulad DP, Doan L, Lee PK and Atanaskova Mesinkovska N: Mohs surgery for the treatment of lentigo maligna and lentigo maligna melanoma-a systematic review. J Dermatolog Treat 32: 157-163, 2021

47. Walling HW, Scupham RK, Bean AK and Ceilley RI: Staged excision versus Mohs micrographic surgery for lentigo maligna and lentigo maligna melanoma. J Am Acad Dermatol 57: 659-664, 2007.

48. Zitelli JA, Brown $\mathrm{C}$ and Hanusa BH: Mohs micrographic surgery for the treatment of primary cutaneous melanoma. J Am Acad Dermatol 37: 236-245, 1997.

49. Stigall LE, Brodland DG and Zitelli JA: The use of Mohs micrographic surgery (MMS) for melanoma in situ (MIS) of the trunk and proximal extremities. J Am Acad Dermatol 75: 1015-1021, 2016.

50. Michielin O, van Akkooi ACJ, Ascierto PA, Dummer R and Keilholz U; ESMO Guidelines Committee. Electronic address: clinicalguidelines@esmo.org: Cutaneous melanoma: ESMO clinical practice guidelines for diagnosis, treatment and follow-up $†$. Ann Oncol 30: 1884-1901, 2019.

51. Hendrickx A, Cozzio A,Plasswilm L and Panje CM: Radiotherapy for lentigo maligna and lentigo maligna melanoma-a systematic review. Radiat Oncol 15: 174,2020.

52. Fogarty GB, Hong A, Economides A and Guitera P: Experience with treating radiotherapy for lentigo maligna with definitive radiotherapy. Dermatol Res Pract 2018: 7439807, 2018.

53. Schmid-Wendtner MH, Brunner B, Konz B, Kaudewitz P, Wendtner CM, Peter RU, Plewig G and Volkenandt $M$ : Fractionated radiotherapy of lentigo maligna and lentigo maligna melanoma in 64 patients. J Am Acad Dermatol 43: 477-482, 2000.

54. Lazarevic D, Ramelyte E, Dummer R and Imhof L: Radiotherapy in periocular cutaneous malignancies: A retrospective study. Dermatology 235: 234-239, 2019.

55. Hedblad MA and Mallbris L: Grenz ray treatment of lentigo maligna and early lentigo maligna melanoma. J Am Acad Dermatol 67: 60-68, 2012.

56. Kopf AW, Bart RS and Gladstein AH: Treatment of melanotic freckle with x-rays. Arch Dermatol 112: 801-807, 1976.

57. Lamoureux A, Ouhabrache N, Coulibaly S, Dousset L, Gerard E, Dutriaux C, Pham-Ledard A, Cogrel O, Trouette R, Beylot-Barry M and Vendrely V: Contact radiotherapy for lentigo maligna and lentigo maligna melanoma: A cohort of 61 cases. Radiother Oncol 127: S436, 2018.

58. Zalaudek I, Horn M, Richtig E, Hödl S, Kerl H and Smolle J: Local recurrence in melanoma in situ: Influence of sex, age, site of involvement and therapeutic modalities. Br J Dermatol 148: 703-708, 2003
59. Farshad A, Burg G, Panizzon R and Dummer R: A retrospective study of 150 patients with lentigo maligna and lentigo maligna melanoma and the efficacy of radiotherapy using Grenz or soft X-rays. Br J Dermatol 146: 1042-1046, 2002.

60. Christie DR and Tiver KW: Radiotherapy for melanotic freckles. Australas Radiol 40: 331-333, 1996.

61. Tsang RW, Liu FF, Wells W and Payne DG: Lentigo maligna of the head and neck. Results of treatment by radiotherapy. Arch Dermatol 130: 1008-1012, 1994.

62. Harwood AR: Conventional fractionated radiotherapy for 51 patients with lentigo maligna and lentigo maligna melanoma. Int J Radiat Oncol Biol Phys 9: 1019-1021, 1983.

63. Robinson M, Primiero C, Guitera P, Hong A, Scolyer RA, Stretch JR, Strutton G, Thompson JF and Soyer HP: Evidence-based clinical practice guidelines for the management of patients with lentigo maligna. Dermatology 236: 111-116, 2020.

64. Papanikolaou M and Lawrence CM: Long-term outcomes of imiquimod-treated lentigo maligna. Clin Exp Dermatol 44: 631-636, 2019.

65. Sampson BP and Bowen GM: Strategies for reducing final surgical defect sizes in the treatment of lentigo maligna. Dermatol Surg 46: 537-545, 2020.

66. Kai AC, Richards T, Coleman A, Mallipeddi R, Barlow R and Craythorne EE: Five-year recurrence rate of lentigo maligna after treatment with imiquimod. Br J Dermatol 174: 165-168, 2016.

67. Astorino S, Astorre P, Pasquini P, Di Nunno D, Pellegrini F and Paolino G: Imiquimod 5\% cream in occlusion, for the treatment of lentigo maligna: A new scheme of short cycles and the need for clinical trials. Dermatol Ther 32: e12757, 2019.

68. Buettiker UV, Yawalkar NY, Braathen LR and Hunger RE: Imiquimod treatment of lentigo maligna: An open-label study of 34 primary lesions in 32 patients. Arch Dermatol 144: 943-945, 2008.

69. Chapman MS, Spencer SK and Brennick JB: Histologic resolution of melanoma in situ (lentigo maligna) with $5 \%$ imiquimod cream. Arch Dermatol 139: 943-944, 2003.

70. Cotter MA, McKenna JK and Bowen GM: Treatment of lentigo maligna with imiquimod before staged excision. Dermatol Surg 34: 147-151, 2008.

71. Wong JG, Toole JW, Demers AA, Musto G and Wiseman MC: Topical 5\% imiquimod in the treatment of lentigo maligna. J Cutan Med Surg 16: 245-249, 2012.

72. Kirtschig G, Van Meurs T and Van Doorn R: Twelve-week treatment of lentigo maligna with imiquimod results in a high and sustained clearance rate. Acta Derm Venereol 95: 83-85, 2015.

73. Gautschi M, Oberholzer PA, Baumgartner M, Gadaldi K, Yawalkar N and Hunger RE: Prognostic markers in lentigo maligna patients treated with imiquimod cream: A long-term follow-up study. J Am Acad Dermatol 74: 81-87.e1, 2016.

74. Read T, Noonan C, David M, Wagels M, Foote M, Schaider H, Soyer HP and Smithers BM: A systematic review of non-surgical treatments for lentigo maligna. J Eur Acad Dermatol Venereol 30: 748-753, 2016.

75. Greveling K, van der Klok T, van Doorn MB, Noordhoek Hegt V and Prens EP: Lentigo maligna-anatomic location as a potential risk factor for recurrences after non-surgical treatment. J Eur Acad Dermatol Venereol 31: 450-454, 2017.

76. Craythorne EE and Lawrence CM: Observational study of topical imiquimod immunotherapy in the treatment of difficult lentigo maligna. Clin Med Oncol 2: 551-554, 2008.

77. Powell AM, Robson AM, Russell-Jones R and Barlow RJ: Imiquimod and lentigo maligna: A search for prognostic features in a clinicopathological study with long-term follow-up. Br J Dermatol 160: 994-998, 2009.

78. Ly L, Kelly JW, O'Keefe R, Sutton T, Dowling JP, Swain S, Byrne M, Curr N, Wolfe R, Chamberlain A and Haskett M: Efficacy of imiquimod cream, 5\%, for lentigo maligna after complete excision: A study of 43 patients. Arch Dermatol 147: 1191-1195, 2011

79. Halse H, Caramia F, McLean CA, Wang M, Aw Yeang HX, Keam SP, Behren A, Ly L, Haskett M, Cebon J, et al: Distinct pretreatment immune gene signature in lentigo maligna is associated with imiquimod response. J Invest Dermatol 140: 869-877.e16, 2020

80. Hyde MA, Hadley ML, Tristani-Firouzi P, Goldgar D and Bowen GM: A randomized trial of the off-label use of imiquimod, $5 \%$, cream with vs without tazarotene, $0.1 \%$, gel for the treatment of lentigo maligna, followed by conservative staged excisions. Arch Dermatol 148: 592-596, 2012. 
81. Donigan JM, Hyde MA, Goldgar DE, Hadley ML, Bowling M and Bowen GM: Rate of recurrence of lentigo maligna with off-label neoadjuvant topical imiquimod, $5 \%$, cream prior to conservatively staged excision. JAMA Dermatol 154: 885-988, 2018.

82. Mora AN, Karia PS and Nguyen BM: A quantitative systematic review of the efficacy of imiquimod monotherapy for lentigo maligna and an analysis of factors that affect tumor clearance. J Am Acad Dermatol 73: 205-212, 2015.

83. Marsden JR, Fox R, Boota NM, Cook M, Wheatley K, Billingham LJ and Steven NM; NCRI Skin Cancer Clinical Studies Group, the U.K. Dermatology Clinical Trials Network and the LIMIT-1 Collaborative Group: Effect of topical imiquimod as primary treatment for lentigo maligna: The LIMIT-1 study. Br J Dermatol 176: 1148-1154, 2017.

84. Rajpar SF and Marsden JR: Imiquimod in the treatment of lentigo maligna. Br J Dermatol 155: 653-656, 2006.

85. Tio D, van der Woude J, Prinsen CAC, Jansma EP, Hoekzema R and van Montfrans C: A systematic review on the role of imiquimod in lentigo maligna and lentigo maligna melanoma: Need for standardization of treatment schedule and outcome measures. J Eur Acad Dermatol Venereol 31: 616-624, 2017.

86. Woodmansee CS and McCall MW: Recurrence of lentigo maligna and development of invasive melanoma after treatment of lentigo maligna with imiquimod. Dermatol Surg 35: 1286-1289, 2009.

87. Ellis LZ, Cohen JL, High W and Stewart L: Melanoma in situ treated successfully using imiquimod after nonclearance with surgery: Review of the literature. Dermatol Surg 38: 937-946, 2012.

88. Brand FL, Seyed Jafari SM and Hunger RE: Confocal microscopy and lentigo maligna: An in vivo pilot study for the assessment of response to imiquimod therapy. Dermatology 235: 150-155, 2019

89. De Moraes AM, Pavarin LB, Herreros F, de Aguiar Michelman F, Velho PE and de Souza EM: Cryosurgical treatment of lentigo maligna. J Dtsch Dermatol Ges 5: 477-480, 2007 (In English, German).

90. Collins P, Rogers S, Goggin M and Manning W: Cryotherapy for lentigo maligna. Clin Exp Dermatol 16: 433-435, 1991.

91. McKenna JK, Florell SR, Goldman GD and Bowen GM: Lentigo maligna/lentigo maligna melanoma: Current state of diagnosis and treatment. Dermatol Surg 32: 493-504, 2006.

92. Karam A, Simon M, Lemasson G and Misery L: The use of photodynamic therapy in the treatment of lentigo maligna. Pigment Cell Melanoma Res 26: 275-277, 2013.

93. Räsänen JE, Neittaanmäki N, Jeskanen L, Pölönen I, Snellman E and Grönroos M: Ablative fractional laser-assisted photodynamic therapy for lentigo maligna: A prospective pilot study. J Eur Acad Dermatol Venereol 34: 510-517, 2020.
94. Lee H, Sowerby LJ, Temple CL, Yu E and Moore CC: Carbon dioxide laser treatment for lentigo maligna: A retrospective review comparing 3 different treatment modalities. Arch Facial Plast Surg 13: 398-403, 2011.

95. Madal V and August PJ: Lentigo maligna-outcomes of treatment with Q-switched Nd:YAG and alexandrite lasers. Dermatol Surg 35: 607-612, 2009.

96. de Vries K, Rellum R, Habets JM and Prens EP: A novel two-stage treatment of lentigo maligna using ablative laser therapy followed by imiquimod. Br J Dermatol 168: 1362-1364, 2013.

97. Fikrle T, Divišová $\mathrm{B}$, Šuchmannová J and Pizinger K: The use of 2940-nm ER:YAG laser for the treatment of lentigo maligna. J Dtsch Dermatol Ges 17: 425-431, 2019.

98. McKenna DB, Cooper EJ, Kavanagh GM, Davie RM, McLaren KM and Tidman MJ: Amelanotic malignant melanoma following cryosurgery for atypical lentigo maligna. Clin Exp Dermatol 25: 600-604, 2000

99. Nazzaro-Porro M, Passi S, Zina G and Breathnach AS: Ten year's experience of treating lentigo maligna with topical azelaic acid. Acta Derm Venereol Suppl (Stockh) 143: 49-57, 1989.

100. Litwin MS, Krementz ET, Mansell PW and Reed RJ: Topical chemotherapy of lentigo maligna with 5-fluorouracil. Cancer 35 721-733, 1975.

101. Ryan RF, Krementz ET and Litwin MS: A role for topical 5-fluorouracil therapy in melanoma. J Surg Oncol 38: 250-256, 1988.

102. Calista D: Treatment of lentigo maligna with topical $1 \%$ cidofovir. Br J Dermatol 157: 421-423, 2007.

103. Montaudié H, Le Duff F, Butori C, Hofman V, Fontas E, Roger-Cruzel C, Bahadoran P, Perrot JL, Desmedt E, Legoupil D, et al: Ingenol mebutate to treat lentigo maligna of the head (face and scalp): A prospective, multicenter, single-arm phase 2 trial indicates no benefit. J Am Acad Dermatol 82: 731-733, 2020

104. Gadaldi K, Feldmayer L, Yawalkar N and Hunger RE: Ingenol mebutate for lentigo maligna: A case report. Dermatology 232 (Suppl 1): S24-S28, 2016.

105. Tio D, Prinsen CAC, Dréno B, Hoekzema R, Augustin M and van Montfrans C: Variation in the diagnosis and clinical management of lentigo maligna across Europe: A survey study among European association of dermatologists and venereologists members. J Eur Acad Dermatol Venereol 32: 1476-1484, 2018 .

This work is licensed under a Creative Commons Attribution-NonCommercial-NoDerivatives 4.0 International (CC BY-NC-ND 4.0) License. 